\title{
Vidas Negras EnCarceradas: a pandemia nas PRISÕES bRASILEIRAs ${ }^{1,2}$
}

Felipe da Silva Freitas ${ }^{3}$

\section{INTRODUÇÃO}

As prisões no Brasil são, em muitos sentidos, um espaço peculiar na demonstração da influência do racismo em nossas relaçóes sociais. Desde o momento da prisão - seja em flagrante, seja como resultado de processos de investigação - até a esfera das decisóes judiciais, da apreciação dos recursos, da apuração de responsabilidades, da identificação dos culpados e na construção da matéria probatória, o racismo atua como um marcador que distancia negros e não negros no que tange à vulnerabilidade perante o sistema de segurança pública e de justiça criminal e que constitui o próprio fundamento e a razão de existência do sistema penal.

O racismo opera como um eixo de relação entre punição, prisão e pessoas negras no Brasil, gerando, em termos estruturais, uma vinculação profunda entre as formas de castigo físico e proliferação de mecanismos de controle público de negras e negros, em especial por meio da segurança pública e da justiça criminal. Em termos teóricos, podemos dizer que as prisóes atualizam os saberes sobre raça e relaçôes raciais na medida em que expressam construtos sociais próprios da experiência colonial controle e castigos físicos, desumanização, superexploração - e, ao mesmo tempo, também cumprem um papel específico na manutenção do sistema de símbolos e representaçóes voltados à reiteração de imagens e estereótipos negativos sobre as pessoas negras - que são o "público preferencial" do sistema carcerário. De acordo com Werneck (2013, p. 3),

o racismo é uma ideologia que se realiza nas relaçóes entre pessoas e grupos, no desenho e desenvolvimento das políticas públicas, nas estruturas de governo e nas formas de organização dos Estados. Ou seja, trata-se de um fenômeno de abrangência ampla e complexa que penetra e participa da cultura, da política e da ética. Para isso requisita uma série de instrumentos capazes de mover os processos em favor de seus interesses e necessidades de continuidade, mantendo e perpetuando privilégios e hegemonias.

Por sua ampla e complexa atuação, o racismo deve ser reconhecido também como um sistema, uma vez que se organiza e se desenvolve através de estruturas, políticas, práticas e normas capazes de definir oportunidades e valores para pessoas e populaçóes a partir de sua aparência.

No âmbito acadêmico, e também em trabalhos de organizaçóes da sociedade civil, de governos e de organismos internacionais, muitas são as pesquisas que tem revelado a dimensão estrutural das hierarquias raciais na construção do fenômeno do hiperencarceramento nos últimos trinta anos no

1. DOI: http://dx.doi.org/10.38116/bapi26art3

2. Agradeço a toda equipe de pesquisadores e pesquisadoras do projeto Infovírus: prisões e pandemia, especialmente às professoras Camila Prando (Universidade de Brasília - UnB), Marília Budó (Universidade Federal de Santa Catarina - UFSC), ao professor Riccardo Cappi (Universidade do Estado da Bahia - UNEB - e Universidade Estadual de Feira de Santana - UEFS), com os quais tenho atuado no monitoramento diário de informações sobre a pandemia no contexto prisional brasileiro.

3. Doutor em Direito, Estado e Constituição pela UnB; integrante do Grupo de Pesquisa em Criminologia da UEFS; e membro da coordenação do projeto Infovírus: pandemia e prisões. 
Brasil. ${ }^{4}$ A seletividade racial cumpre um papel decisivo no incremento das taxas de encarceramento por meio tanto da seletividade policial quanto da desigual taxa de condenaçóes de negros e brancos no âmbito da justiça criminal, como tem sido apontado em séries de pesquisas quantitativas desde a década de 1990 (Adorno, 1995 e 1996; Lima, 2004; Paixão, 2008; DPERJ, 2020).

$\mathrm{Na}$ realidade, o sistema penal, mesmo quando alcança pessoas brancas, está estruturalmente voltado para a preservação de práticas violentas experimentadas contra pessoas negras, conformando um peculiar exemplo do racismo institucional que resulta no amoldamento das formas e da maneira de agir das instituiçóes com vistas à reiteraçáo de métodos violentos, abusivos e discriminatórios contra um grupo social historicamente excluído. Como destaca Flauzina (2017), o racismo não é uma mera característica agregada ao sistema punitivo brasileiro; é o fundamento do modelo jurídico que se criou no país e que, historicamente, produz sujeição e multiplica vulnerabilidades.

Se o sistema foi estruturado a partir e para o controle da populaçáo negra, a maneira como sua movimentação se dá está também atrelada ao segmento. A forma como nosso sistema penal incide sobre os corpos está condicionada pela corporalidade negra, na negação de sua humanidade. (...). Assim, o racismo deu o tom e os limites à violência empreendida pelo sistema penal, e este a carrega consigo na direção de toda clientela a que se dirige. É o racismo que controla o potencial de intervenção física do sistema: daí toda sua agressividade. (...) Apesar de existir uma diferença inquestionável entre o tratamento conferido a brancos e negros pelo sistema penal, o fato é que o racismo o conformou como instrumento que age pela violência, que acaba por atingir todos os indivíduos com os quais se relaciona. Quando o sistema entra em contato com corpos brancos também o faz por meio da violência, mas o faz por ser esta mediação assumida por suas práticas condicionadas pelo racismo.

Assim, podemos afirmar que as prisóes no Brasil são repositórios precários de pessoas nos quais atualiza-se não só a experiência de inferiorização e exclusão política e social de pessoas negras, mas também um espaço em que se alarga o risco de morte, física e simbólica, dessas pessoas e o seu desmoronamento do ponto de vista político e subjetivo (Flauzina, 2017; Duarte e Freitas, 2019; Davis, 2018).

A pandemia expôs os níveis radicais de precariedade e violência vividos no âmbito do sistema carcerário brasileiro e evidenciou aspectos muito marcantes do racismo brasileiro. Como destacou o próprio Supremo Tribunal Federal (STF) no julgamento da Arguição de Descumprimento de Preceito Fundamental (ADPF) 347,, o quadro no sistema prisional é de permanente e estrutural violação de direitos com um contexto de "superlotação, torturas, homicídios, violência sexual, celas imundas e insalubres, proliferaçáo de doenças infectocontagiosas, comida imprestável, falta de água potável e de produtos higiênicos básicos" "gerando uma situação em que é previsível que haja uma maior vulnerabilidade à infecção e doença.

Neste artigo, pretende-se analisar as reações estatais à chegada da contaminação por Covid-19 nas prisóes, sublinhando as açóes do governo federal e das administraçóes prisionais nos estados

\footnotetext{
4. A título de exemplo, citamos: Carvalho, 2015.; Duarte et al., 2014. p. 81-118.; Sinhoretto, Silvestre, Schlitter, 2014.

5. A ADPF 347 é um caso paradigmático no debate sobre a situação do sistema carcerário brasileiro pois, nessa ação, requereu-se que o Supremo reconhecesse o estado de coisas inconstitucional das prisões do país e que adotasse medidas para minorar os efeitos desse quadro de violência estrutural. Disponível em: <http://www.stf.jus.br/portal/cms/verNoticiaDetalhe.asp?idConteudo=439614>. 6. STF, Medida Cautelar (MC)-ADPF 347. Relator: Ministro Marco Aurélio. Disponível em: <http://redir.stf.jus.br/paginadorpub/paginador. jsp? docTP=TP\&docID=10300665>.
} 
e as tendências das decisóes judiciais relativas às pessoas privadas de liberdade no contexto da pandemia. A partir das informaçóes apresentadas pelo projeto Infovírus: pandemia e prisóes ${ }^{7}$ e de outras organizaçóes dedicadas ao monitoramento da situação prisional ${ }^{8}$ este texto tem como objetivo indicar as omissóes estatais no campo das políticas penitenciárias, indicando seus impactos sobre a população privada de liberdade.

\section{PAPEL DA ADMINISTRAÇÃO PRISIONAL NA CONDUÇÃO DA PANDEMIA DE COVID-19 NA PRISÃO}

A resposta estatal à pandemia nas prisóes - assim como na maioria das áreas de políticas públicas foi débil, desarticulada e ineficaz. Já nas primeiras semanas após o registro dos primeiros casos de Covid-19 no Brasil, o governo federal e as administraçóes prisionais nos estados apressaram-se em negar o risco de um iminente alastramento da pandemia nas unidades de privação de liberdade, mesmo não havendo medidas compatíveis em termos de prevenção. Em artigo publicado no jornal o Estado de São Paulo em 30 de março de 2020 o então ministro da justiça e segurança pública, Sérgio Moro, e o então Diretor Geral do Departamento Penitenciário Nacional (DEPEN), Fabiano Bordignon, defenderam que "colocá-los (os presos) nas ruas ou em prisão domiciliar trará mais riscos para essa população, além de repercutir em graves riscos para a segurança pública.” (Moro e Bordignon, 2020)

As principais açóes anunciadas pelo DEPEN no contexto da pandemia foram, segundo informes veiculados na página do próprio Departamento: i) suspender as visitas, assistência religiosa e atendimento com advogados, como meio de conter a contaminação; ii) editar a portaria $\mathrm{n}^{\circ}$ 143, de 25 de março de $2020^{9}$ para viabilizar a destinação de R \$ 107 milhóes via Fundo a Fundo, para custeio e investimento de açóes de enfrentamento à pandemia; iii) coordenar a distribuição de donativos de equipamentos de proteção individual (EPIs) e materiais de limpeza; e iv) publicar um painel de monitoramento das medidas contra a Covid-19, com informaçóes sobre suspeitas, detecçóes, óbitos, testes e pessoas recuperadas no sistema e as ações adotadas pelos administraçóes prisionais nos estados.

Trata-se de anúncios importantes que poderiam, se devidamente monitorados, conseguir a estabilização do sistema prisional no contexto da pandemia. Todavia, os anúncios oficiais não se concretizaram conforme descrito na página do ministério. O que fora prometido não foi efetivamente executado e, quando realizado, muito do que foi feito pelo DEPEN resultou em maior acirramento das relaçóes no ambiente prisional.

A suspensão das visitas, por exemplo, bloqueou informaçóes de familiares e amigos de pessoas presas sobre a situação dos presos e gerou sérios agravos à saúde mental das pessoas encarceradas (FGV e NEB, 2020). A falta de informaçóes tem ensejado recorrentes manifestaçóes dos familiares

7. 0 Infovírus é uma iniciativa do Centro de Estudos de Desigualdade e Discriminação (CEDD), da Universidade de Brasília (UnB); Grupo Asa Branca de Criminologia, da Universidade Federal de Pernambuco (UFPE) e Universidade Católica de Pernambuco (Unicap); Grupo de Pesquisa em Criminologia, da Universidade do Estado da Bahia/Universidade Estadual de Feira de Santana (UNEB/UEFS); e Grupo Poder Controle e Dano Social, da Universidade Federal de Santa Catarina/Universidade Federal de Santa Maria (UFSC/UFSM) e de pesquisadores e pesquisadoras autônomos que pretendem contribuir com informação de qualidade sobre as prisões e sobre o impacto da pandemia de coronavírus no Brasil (Ver <https://twitter.com/INFOVIRUSpp> e <https://www.instagram.com/infovirusprisoes $>$ ).

8. Também foram consultados para este texto as informações veiculadas pela plataforma Covid nas Prisões, mantida pela Organização não Governamental (ONG) Iser (disponível em: <http://www.covidnasprisoes.com>) e pelas redes sociais (twitter e instagram) da Frente Nacional e das Frentes Estaduais pelo Desencarceramento, que reúnem lideranças do movimento de familiares de pessoas privadas de liberdade. 9. Informação disponível em: <https://www.gov.br/depen/pt-br/assuntos/acoes-contra-pandemia/prevencao-ao-covid-19-no-sistema-prisionalinformacoes-complementares $>$. Acesso em 10 set. 2020. 
de presos. No monitoramento diário das informaçóes realizado pelo projeto Infovírus registram-se manifestaçóes de familiares em mais de dez estados, em muitos casos com a ocorrência de atos públicos na porta das unidades prisionais e denúncias de falta de informaçóes desde março, quando foram suspensas as visitas. ${ }^{10}$

Quanto a questão orçamentária, nota-se um baixo grau de transparência na aplicação dos recursos conforme a finalidade apontada, assim como uma redução da efetividade na aplicação dos respectivos valores. De acordo com o registro realizado pelo projeto Infovírus, há inclusive utilização de recursos voltados para medidas de proteção à pandemia sendo utilizados para fins completamente diversos daqueles inicialmente destinados. ${ }^{11}$ No estado do Rio de Janeiro, por exemplo, identificou-se uma autorização do diretor de políticas penitenciárias do DEPEN para aprovação de crédito extraordinário de $\mathrm{R} \$ 19$ milhóes para aquisição de material não letal (compra de granada (sic), munições e espargidores) com a vistas a subsidiar a prevenção de tumultos devido a suspensão de visitas em razão da Covid-19. ${ }^{12}$

Também não houve por parte do DEPEN, e de nenhuma administração estadual, um programa de testagem em massa de presos e de servidores, tampouco desenvolveu-se uma estratégia eficaz de distanciamento físico nas unidades, como atestam vários informes de inspeçóes e visitas técnicas realizadas desde março de $2020 .{ }^{13}$ De acordo com dados do próprio painel do DEPEN, em 31 de agosto de 2020 apenas cerca de $8 \%$ da população prisional do país fora testada para Covid-19. ${ }^{14}$

Outro aspecto marcante ao analisarmos as ações de prevenção à Covid-19 nas prisões é a constatação da falta de dados sobre a evolução dos números da pandemia. Mesmo com o painel mantido pelo DEPEN, faltam informaçóes sobre as características das pessoas testadas (gênero, raça e comorbidades) e sobre as unidades prisionais em que os testes têm sido realizados (Pires, 2020). Essas informaçóes, cruciais para se aferir a consistência diária dos dados divulgados, estáo ausentes nas plataformas do governo federal, como apontam os especialistas que monitoram diariamente os dados da Covid nas prisóes. Em postagem do dia 22 de abril, o projeto Infovírus ${ }^{15}$ destacou o que se segue.

- Não se sabe qual é a metodologia adotada para conferir os casos suspeitos ou detectados e os óbitos.

- As informaçóes do painel não abrangem os policiais penais e o pessoal administrativo das unidades prisionais suspeitos ou detectados com coronavírus. Além disso, não há informaçóes sobre o protocolo de realizaçấo de testes de Covid-19 entre os detentos e trabalhadores do sistema prisional.

- A redução no número de casos detectados nos dados do painel não é acompanhada de um registro histórico. Por exemplo, doentes que são retirados das unidades prisionais pela doença somem dos

10. No estado de São Paulo, por exemplo, quase $70 \%$ dos familiares de pessoas presas afirmaram não ter informações ou contato com parentes presos desde o início da pandemia (NEB, 2020).

11. Disponível em: <https://www.instagram.com/p/CAqmV7KHFei/>. Acesso em 2 set. 2020.

12. Ministério da Justiça e Segurança Pública. Despacho no 3710/2020/DIRPP/DEPEN/MJ. Disponibilização de verba para sanitização de unidades prisionais. 25 de maio de 2020 (disponível na plataforma SEl. Chave de autenticidade: código verificador 11761355; e o código CRC A9F3FC68). 13. Sobre os relatos de descaso estatal em relação a situação dos presídios no contexto da pandemia e sobre a baixa qualidade das medidas de prevenção ver os inúmeros relatórios disponibilizados nos sites: Covid na Prisões (<https://www.covidnasprisoes.com/relatorios $>$ ); Mecanismo Estadual de Prevenção e Combate a Tortura do Rio de Janeiro (<http://mecanismorj.com.br/relatorios/>); e Mecanismo Nacional de Prevenção e Combate à Tortura (<https://mnpctbrasil.wordpress.com/relatorios/>). Ver também o Comunicado no 195/2020 da Comissão Interamericana de Direitos Humanos, que manifesta preocupação pela situação das pessoas privadas de liberdade no Brasil diante da pandemia de Covid-19. 14. Disponivel em: <https://app.powerbi.com/view?r=eyJrljoiYThhMjk5YjgtZWQwYS000DIkLTg4NDgtZTFhMTgzYmQ2MGVIliwidCI6ImViMDk WNDIwLTQ0NGMtNDNmNy05MWYyLTRIOGRhNmJmZThIMSJ9>. Consulta em 31 ago. 2020.

15. Disponível em: <https://www.instagram.com/p/B_Su9laBi8m/>. Acesso em 1o- de set. 2020. 
números de casos confirmados. Isso gera uma redução de casos que não representa a realidade. Da mesma forma, se a pessoa contraiu a doença na prisão e morreu fora dela, não há contabilização dessa morte no painel.

- Não existem rastros verificáveis das movimentaçôes de presos doentes. Tudo indica que o painel não busca mostrar os dados da realidade do sistema penitenciário nacional na crise do novo coronavírus, mas sim confirmar - falsamente - o discurso do Ministério da Justiça de que não há crise, de que "está tudo sob controle".

No âmbito dos estados, a informação acerca da situação nos presídios também é precária. Em levantamento feito pela pesquisadora Natália Pires (Instituto de Ensino e Pesquisa - Insper) constata-se que oito estados náo divulgam qualquer acompanhamento sobre a Covid no sistema prisional em suas páginas eletrônicas e apenas dez dedicam espaço específico a esses dados nas páginas das secretarias de administração penitenciária. ${ }^{16}$

\section{O DESCUMPRIMENTO DA RECOMENDAÇÃO CNJ № 62/2020 E A POSTURA DO PODER JUDICIÁRIO FRENTE A PANDEMIA}

No âmbito do poder judiciário, a principal normativa no contexto da pandemia foi a Recomendação no 62/2020 do Conselho Nacional de Justiça (CNJ), que exortou os tribunais de justiça para tornarem excepcional a conversão de flagrantes em prisóes preventivas (devendo ser aplicada, se for o caso, apenas para os crimes violentos) e reavaliar as prisões preventivas, sobretudo em relação a: i) grávidas, lactantes ou em situação de vulnerabilidade social ou de saúde; ii) presos em unidades superlotadas; e iii) presos preventivamente há mais de noventa dias. No âmbito da execução penal, a recomendação sugere que se conceda saídas antecipadas a presos em regime fechado e semiaberto; e conceder prisáo domiciliar a todos os presos em regime semiaberto.

As medidas propostas pelo CNJ têm como objetivo preservar a vida e a integridade das pessoas sob custódia do Estado e foi enfaticamente saudada por organizaçóes de direitos humanos e por organismos de cooperação internacional. ${ }^{17}$ Entretanto, o Poder Judiciário tem se recusado a conceder pedidos de prisão domiciliar para pessoas integrantes do grupo de risco, e predominam os casos de indeferimento dos habeas corpus impetrados (Balthazar, 2020; Machado e Vasconcelos, 2020; Valença e Freitas, 2020; Moser e Budó, 2020).

Ainda que sejam completamente contrários à Constituição, incompatíveis com a força normativa da Recomendaçáo no $62 / \mathrm{CNJ}$ e, na prática, ponham em risco pessoas que estão potencialmente vulneráveis com a infecção por Covid-19, os argumentos mais utilizados pelos juízes para indeferir os pedidos de transferência para prisão domiciliar são que: i) o paciente não demonstrou que pertence ao grupo de risco; ii) o paciente não demonstrou que a penitenciária está incapacitada de realizar

16. Disponível em: <https://www.covidnasprisoes.com/blog/stf-contraria-o-cnj-e-nega-80-8-dos-habeas-corpus-baseados-na-pandemiade? categoryld=148846>. Acesso em: 2 de set. 2020.

17. Em 1 o de abril de 2020 o Sr. Jan Jarab, representante regional para América do Sul do Alto Comissariado das Nações Unidas para os Direitos Humanos (ACNUDH), escreveu ao Sr. Dias Toffoli, presidente do CNJ, saudando o Brasil pela edição da Recomendação CNJ no 62/2020 e afirmando que ela coincidia com as recomendações do Sub-Comitê da Organização das Nações Unidas (ONU) para Prevenção à Tortura. Em 11 de abril, mais de setenta organizações da sociedade civil brasileira manifestaram-se no mesmo sentido do ACNUDH, saudando a iniciativa do CNJ em relação aos presídios no contexto da pandemia (Mais..., 2020). 
atendimento de saúde de qualidade; e iii) a penitenciária na qual o paciente se encontra recolhido não possui casos de Covid-19. ${ }^{18}$

Segundo pesquisa realizada pelo Insper e a pela FGV-SP, que avaliou 6.781 habeas corpus impetrados no Tribunal de Justiça de Sáo Paulo (TJSP) em razão da pandemia, o que se vê diante dos casos é a majoritária denegação da liberdade em $88 \%$ dos casos. Assim como nos dados divulgados pela Defensoria Pública do estado de São Paulo (7 de junho de 2020) o que se constata na pesquisa FGV/INSPER é que entre março e maio de 2020 houve um aumento dos habeas corpus concedidos no TJSP, todavia, não mediante o acolhimento do argumento da crise sanitária, mas apenas tratando de casos de presos detidos em caráter preventivo, ainda sem julgamento, por crimes cometidos sem violência ou casos em que se encontravam condenados a regime semiaberto e aberto de prisão (Machado e Vasconcelos, 2020). Ou seja, casos nos quais já havia uma ilegalidade na prisão independentemente da ocorrência da pandemia.

Segundo levantamento realizado pelo site de notícias jurídicas Jota, no painel do STF sobre a Covid-19, eram 4.058 processos sobre o tema até 7 de agosto. Desse total, mais da metade são habeas corpus (2.930), dos quais 80,8\% (2.366) foram negados. Apenas 7,76\% (315) foram registrados como liminar deferida ou procedente. ${ }^{19}$ Decidindo dessa forma, o STF legitima a manutenção do hiperencarceramento, que é o principal responsável pelo alastramento do vírus nas prisóes.

\section{CONSIDERAÇÕES FINAIS}

A postura estatal na gestão das medidas de controle da pandemia nos presídios brasileiros reflete o sistemático descaso em relação às pessoas negras no Brasil. Trata-se da radicalização da realidade historicamente denunciada por organizaçôes do movimento negro, com a máxima exposição de pessoas negras a risco de morte, sem a adoção das medidas adequadas para prevenção e para a assistência daqueles que já estejam contaminados.

A inversão dessa realidade exigiria, antes de quaisquer outras medidas, uma rápida e imediata ação massiva de desencarceramento tanto para enfrentar o problema da superlotação, que impede medidas adequadas de assepsia e distanciamento físico para controle do vírus, como também para proteger pessoas integrantes do grupo de risco que estejam privadas de liberdade (idosos, pessoas com comorbidades, mulheres grávidas ou puérperas). Além disso, medidas de redução da superlotação carcerária contribuiriam para o enfrentamento às sistemáticas violaçôes de direitos dentro do sistema prisional, que, em si, já constitui uma causa estrutural de violência e de letalidade.

É preciso, também, situar um novo papel para as administraçóes prisionais, tanto nos estados quanto no DEPEN (no âmbito da articulação nacional), firmando metas de assistência à saúde na perspectiva integral e também no que se refere à transparência acerca das condições das unidades prisionais. O contato permanente com a família, a garantia de acesso à defesa e à assistência religiosa

18. Em pesquisa desenvolvida em parceria com a professora Manuela Abath Valença (UFPE), identificamos, a partir da análise dos julgados do STJ, no contexto da pandemia, grupos de argumentos recorrentes na apreciação dos pedidos de liberdade baseados na Recomendação no 62/CNJ. Além dos já expostos no texto, identificamos também os seguintes argumentos: i) não se demonstra que estar preso vulnerabiliza mais o paciente do que estar solto; ii) o paciente demonstrou que compõe grupo de risco, mas cometeu crime grave; iii) o paciente não preenche todos os requisitos do artigo 5, inciso I da Recomendação no 62, estando em unidade superlotada, porém, com equipe médica disponível, por exemplo; iv) supressão de instância (que consiste em não respeitar a hierarquia entre os tribunais); e v) embora reconheça a supressão de instância e deixe de julgar o pedido, recomendando ao tribunal local que volte a apreciar o caso (Valença e Freitas, 2020).

19. Disponível em: <https://www.covidnasprisoes.com/blog/stf-contraria-o-cnj-e-nega-80-8-dos-habeas-corpus-baseados-na-pandemiade? categoryld=148846>. Acesso em 2 de set. 2020. 
e a manutenção de canais de denúncia para casos de torturas, maus tratos, abusos e toda sorte de situação desumana e degradante são deveres do Estado brasileiro que não estáo suspensos no contexto da pandemia; muito pelo contrário, são também importantes salvaguardas que, se forem garantidas, podem colaborar para o aprimoramento do debate público sobre a questáo prisional.

\section{REFERÊNCIAS}

ADORNO, S. Discriminação racial e justiça criminal em São Paulo. Novos Estudos Cebrap, São Paulo, n. 43, 1995.

Racismo, criminalidade violenta e justiça penal: réus brancos e negros em perspectiva comparada. Estudos Históricos, Rio de Janeiro, n. 18, p. 283-300, 1996.

BALTHAZAR, R. Juízes tratam presos com rigor ao analisar pedidos de soltura na pandemia. Folha de Sáo Paulo, São Paulo, 7 de junho de 2020.

CARVALHO, S. O encarceramento seletivo da juventude negra brasileira: a decisiva contribuição do poder judiciário. Revista da Faculdade de Direito da UFMG, Belo Horizonte, n. 67, p. 623-652, jul./dez. 2015.

DAVIS, A. Estarão as prisóes obsoletas? Rio de Janeiro: Difel, 2018.

DPERJ - DEFENSORIA PÚBLICA DO ESTADO DO RIO DE JANEIRO. Perfil dos entrevistados pela Defensoria Pública do Rio de Janeiro nas audiências de custódia entre setembro de 2017 e setembro de 2019. Rio de Janeiro, ago. 2020. Disponível em: <https://sistemas.rj.def.br/publico/ sarova.ashx/Portal/sarova/imagem-dpge/public/arquivos/relat\%C3\%B3rio_audi\%C3\%AAncias_ de_cust\%C3\%B3dia_2017-2019_-_7v.pdf>.

DUARTE, E. C. P.; FREITAS, F. S. Racism and drug policy: criminal control and the management of Black bodies by the brazilian state. In: KORAM, K. (org.). The war on drugs and the global colour line. London: Pluto Press, 2019.

DUARTE, E. C. P. et al. Quem é o suspeito do crime de tráfico de drogas? Anotações sobre a dinâmica de preconceitos raciais e sociais na definição de condutas de usuários e traficantes pelos policiais militares das cidades de Brasília, Curitiba e Salvador. In: LIMA, C.; BAPTISTA, G.; FIGUEIREDO, I. (Orgs.). Segurança pública e direitos humanos: temas transversais. Brasília: Ministério da Justiça, 2014. p. 81-118.

FLAUZINA, A. L. P. Corpo negro caído no cháo: o sistema penal e o projeto genocida do Estado brasileiro. 2. ed. Brasília: Brado Negro, 2017.

LIMA, R. S. de. Atributos raciais do funcionamento do sistema de justiça criminal paulista. Sáo Paulo em Perspectiva, v. 18, n. 1, p. 60 - 65, 2004.

MACHADO, M. R.; VASCONCELOS, N. P. Encarcerar até o vírus: decisões judiciais ignoram os efeitos da Covid-19 na população prisional. Quatro cinco um, São Paulo, jul. 2020. Disponível em: <https://quatrocincoum.folha.uol.com.br/br/artigos/l/encarcerar-ate-o-virus >. Acesso em: 27 jul. 2020. 
MAIS de 70 entidades apoiam Recomendação 62 do CNJ. Revista Consultor Jurídico, São Paulo, 11 de abril de 2020. Disponível em: <https://www.conjur.com.br/2020-abr-11/70-entidades-apoiamrecomendacao-62-cnj>. Acesso em 29 set. 2020.

MORO, S.; BOURDiGNON, F. Prisões, coronavírus e 'solturavírus'. Estado de São Paulo, São Paulo, 30 março 2020.

MOSER, M.; BUDÓ, M. de N. Que pandemia? Superior Tribunal de Justiça mantém padrão de decisóes sobre prisóes preventivas para gestantes, mães de crianças e responsáveis por pessoas com deficiência. Covid nas prisóes, 21 set. 2020. Disponível em: <https:/www.covidnasprisoes.com/ $\mathrm{blog} /$ stj-mantem-padrao-de-decisoes-sobre-prisoes-preventivas-para-mulheres?categoryId=184056> . Acesso em 29 set. 2020.

NEB - NÚCLEO DE ESTUDOS DA BUROCRACIA. Os agentes prisionais e a pandemia de Covid-19. São Paulo: FGV, jun. 2020. (Nota Técnica).

PAIXÃO, M. Vitimização, acesso à justiça e políticas de promoção da igualdade racial. In: PAIXÃO, M. et al. (Orgs.) Relatório anual das desigualdades raciais no Brasil. Rio de Janeiro: Garamond, 2008.

PIRES, N. Sem notícias da prisão. Folha de São Paulo, São Paulo, 22 de agosto de 2020.

SINHORETTO, J.; SILVESTRE, G.; SCHLITTER, M. C. Desigualdade racial e segurança pública em Sáo Paulo: letalidade policial e prisóes em flagrante. Relatório de Pesquisa, São Paulo: GEVAC/UFSCar, 2014.

VALENÇA, M. A.; FREITAS, F. S. O direito à vida e o ideal de defesa social em decisóes do STJ no contexto da pandemia da COVID-19. Revista Direito Público, [S.1.], v. 17, n. 94, nov. 2020. Disponível em: <https://portal.idp.emnuvens.com.br/direitopublico/article/view/4593>.

WERNECK, J. Racismo institucional: uma abordagem conceitual. São Paulo: GELEDÉS, 2013. 